\title{
Construccion de un prototipo anaerobio para el tratamiento de aguas residuales
}

\section{Construction of an anaerobic prototype for the treatment of wastewater}

\author{
RODRIGUEZ-MORALES, José Alberto $\dagger^{1}$, SILVA- GARCIA, Gabriela Guadalupe ${ }^{2}$, RAMOS-LOPEZ, \\ Miguel Ángel ${ }^{2}$ y LEDESMA-GARCIA, Janet ${ }^{1}$ \\ ${ }^{1}$ Universidad Autónoma de Querétaro, Facultad de Ingeniería \\ ${ }^{2}$ Universidad Autónoma de Querétaro, Facultad de Química
}

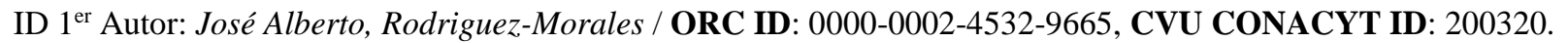

ID $1^{\text {er }}$ Coautor: Gabriela Guadalupe, Silva- Garcia / ORC ID: 0000-0002-9352-6695, CVU CONACYT ID: 302520.

ID $2^{\text {do }}$ Coautor: Miguel Ángel, Ramos-Lopez / ORC ID: 0000-0002-7105-5039, CVU CONACYT ID: 86826.

ID $3^{\text {er }}$ Coautor: Janet, Ledesma-Garcia / ORC ID: 0000-0002-0677-4280, CVU CONACYT ID: 104183

DOI: $10.35429 / J O I E .2019 .11 .3 .29 .41$

Recibido 16 de Junio, 2019; Aceptado 30 de Septiembre, 2019

\section{Resumen}

Se ha propuesto sistemas que se adapten de forma económica y técnica a las condiciones de la mayoría de lugares que tienen un consumo de agua considerable. El trabajo consistió en un reactor biológico anaerobio en el que se llevó a cabo el tratamiento del agua residual doméstica. Se alcanzaron las características de sedimentación del lodo activado después del segundo periodo de estabilización. A lo largo del tratamiento se caracterizaron tres muestras (llave, efluente e influente) en tres tiempos de retención hidráulica, de las cuales se analizaron: $\mathrm{pH}$, temperatura, conductividad, turbidez, SST y DQO. Adicionalmente las muestras se analizaron en laboratorio, para determinar DQO, DBO5, grasas y aceites, y coliformes fecales. Con el sistema diseñado se obtuvieron porcentajes de remoción mayores de $45 \%$ (muestra de la llave) y $34 \%$ (muestra del efluente) para DQO y mayores de $71 \%$ (muestra de la llave) y $57 \%$ (muestra del efluente) para SST. Los parámetros analizados cumplieron los límites máximos permisibles establecidos en la NOM-003-SEMARNAT-1997 y en el PROY-NOM-001-Semarnat-2017. Se instaló un sistema de filtración que aumentó los porcentajes de remoción en las muestras tratadas alcanzando una mejor calidad del agua. También se adiciono cloro para asegurar la eliminación de coliformes fecales.

Tratamiento, Anaerobio, Lodos

\begin{abstract}
It has been proposed systems that adapt economically and technically to the conditions of most places that have a considerable water consumption. The work consisted of an anaerobic biological reactor in which the treatment of domestic wastewater was carried out. Sedimentation characteristics of the activated sludge were achieved after the second stabilization period. Throughout the treatment three samples were characterized (key, effluent and influent) in three times of hydraulic retention, of which were analyzed: $\mathrm{pH}$, temperature, conductivity, turbidity, SST and COD. Additionally, the samples were analyzed in the laboratory to determine COD, BOD5, fats and oils, and fecal coliforms. With the designed system removal percentages higher than 45\% (key sample) and 34\% (effluent sample) were obtained for COD and greater than $71 \%$ (key sample) and 57\% (effluent sample) for SST. The parameters analyzed met the maximum permissible limits established in NOM-003SEMARNAT-1997 and in PROY-NOM-001Semarnat-2017. A filtration system was installed that increased the percentages of removal in the treated samples reaching a better water quality. Chlorine was also added to ensure the elimination of fecal coliforms.
\end{abstract}

Treatment, Anaerobic, Sludge

Citación: RODRIGUEZ-MORALES, José Alberto, SILVA- GARCIA, Gabriela Guadalupe, RAMOS-LOPEZ, Miguel Ángel y LEDESMA-GARCIA, Janet. Construccion de un prototipo anaerobio para el tratamiento de aguas residuales. Revista de Ingeniería Innovativa. 2019. 3-11: 29-41

\footnotetext{
*Correspondencia al Autor (Correo electrónico: josealberto970@ @otmail.com)

$\dagger$ Investigador contribuyendo como primer Autor.
} 


\section{Introducción}

En esta investigación se tiene en cuenta la importancia el crecimiento acelerado de la población y la industrialización han derivado en una explotación insostenible de los recursos naturales; el agua siendo uno de los recursos más importantes por su papel tan indispensable para el desarrollo de la vida se encuentra en desventaja por su disponibilidad mundial.

\section{Sistemas anaerobios para tratamiento de aguas}

Como bien se ha explicado anteriormente, estos sistemas se basan en la depuración biológica por microorganismos anaerobios en un ambiente carente de oxígeno. La descomposición de la materia orgánica se lleva a cabo a partir de reacciones óxido-reducción.

Cuando la materia orgánica como la glucosa $\left(\mathrm{C}_{6} \mathrm{H}_{12} \mathrm{O}_{6}\right)$ ha sido parcialmente oxidada, se da lugar a compuestos completamente oxidados $\left(\mathrm{CO}_{2}\right)$ y compuestos completamente reducidos $\left(\mathrm{CH}_{4}\right.$ e $\left.\mathrm{H}_{2}\right)$. La degradación de la materia orgánica se efectúa en cuatro pasos: hidrólisis, acidogénesis, acetogénesis y metanogénesis.

En estas etapas los microorganismos oxidan determinados compuestos orgánicos para obtener energía para su desarrollo y utilizan compuestos carbonados específicos para sintetizar sus componentes celulares. Los productos finales de estas reacciones son el alimento del siguiente grupo de microorganismos como se muestra en la Figura 1.

a. Hidrólisis. Las bacterias fermentativas actúan en el exterior celular, liberando enzimas (exoenzimas) que se encargan de solubilizar los compuestos orgánicos iniciales. Las proteínas son degradadas por medio de poli-péptidos para producir aminoácidos. Los carbohidratos se transforman en azúcares solubles y los lípidos en ácidos grasos de cadena larga. La hidrólisis es una etapa limitante para el proceso anaerobio $y$ es altamente dependiente de la temperatura. b. Acidogénesis. En esta etapa, los productos de la hidrólisis (compuestos orgánicos solubles como aminoácidos, polisacáridos y ácidos grasos) son transformados en ácidos orgánicos como ácido acético, propiónico y butírico por bacterias acidogénicas que actúan inmediatamente después de la hidrólisis. Son las más beneficiadas energéticamente ya que tienen las más altas velocidades de crecimiento del consorcio. Los principales microorganismos son los que producen ácido butírico del género Clostridium.

c. Acetogénesis. Las bacterias acetogénicas convierten los productos intermedios de la fase anterior (como butirato, propionato, acetato) en ácido acético, hidrógeno y $\mathrm{CO}_{2}$, que son los sustratos principales para la producción del metano.

d. Metanogénesis. Los microorganismos metanogénicos pueden considerarse como los más importantes del proceso, ya que son los encargados de la formación del metano y de la eliminación de los productos de los grupos anteriores. A partir del ácido acético y de las mezclas de $\mathrm{H}_{2}$ y $\mathrm{CO}_{2}$, se produce $\mathrm{CH}_{4}$, también puede formarse ácido fórmico y metanol.

Esta etapa, también conocida como "fermentación metánica"; es la más tardada ya que las bacterias que se encargan de llevar a cabo la fermentación tienen una tasa de crecimiento más lenta que las bacterias de las etapas anteriores. Por este motivo, la fermentación metánica es la que controla la velocidad del proceso.

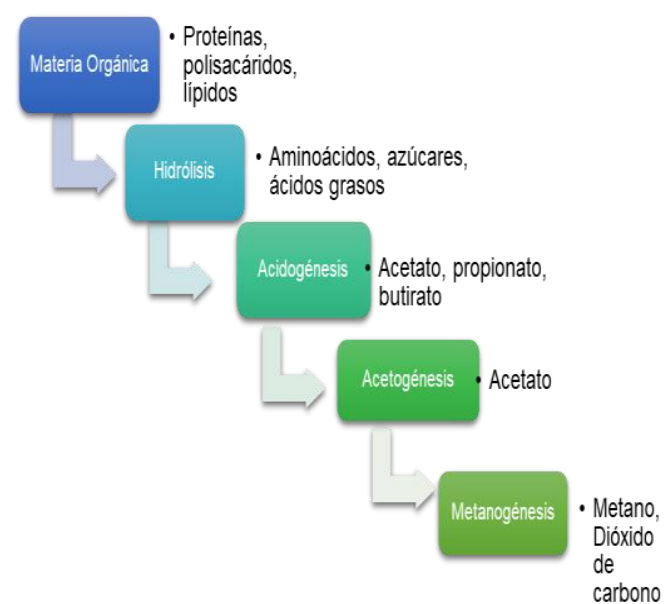

Figura 1 Compuestos formados en las etapas de la digestión anaerobia 


\section{Biopelículas anaerobias}

Los sistemas de biopelículas, también conocidos como "filtros anaerobios o filtros sumergidos", se basan en la formación de consorcios de microorganismos adheridos en diversas superficies sólidas. En estos sistemas, la alimentación de agua residual se lleva a cabo por el fondo del reactor y la salida por la parte superior; de manera que el material de soporte queda sumergido en el agua residual. No es necesaria la recirculación, puesto que la biomasa permanece adherida al material de soporte y no se pierde en el efluente. Las bacterias se agregan en colonias con el objetivo de buscar protección ante posibles condiciones adversas del medio. A diferencia de los sistemas de biomasa móvil, las biopelículas presentan mayor persistencia en el sistema, mayores tasas de crecimiento, mayor incremento en la actividad metabólica y mayor resistencia a la toxicidad.

El tipo de empaque o material de soporte puede diferir dependiendo del diseño del tren de tratamiento pero su principal función es favorecer la adhesión de los microorganismos y la formación de una película biológica activa.

Para el material de soporte se opta generalmente por empaques geométricos acomodados de una forma ordenada, sin embargo algunos pueden ser de orden aleatorio. Normalmente, la alimentación del reactor es por la parte inferior para asegurar que el agua tenga contacto completamente con el material de soporte. Los procesos de tratamiento anaerobio de biomasa fija son principalmente:

- Reactor anaerobio de lecho empacado de flujo ascendente

- Reactor anaerobio de lecho expandido

- Reactor anaerobio de lecho fluidizado.

El uso de biopelículas representa una gran ventaja ya que las bacterias se adhieren en consorcios en las superficies sólidas del empaque, favoreciendo ciertos procesos metabólicos de las bacterias. Al elegirse el material de soporte de biopelículas es necesario considerar que debe conseguirse una alta actividad donde pueda darse una buena difusión de nutrientes en la superficie del material de soporte. Es indispensable que la biopelícula sea estable, delgada y activa para que el proceso tenga un mejor rendimiento.

\section{PET como material de soporte en biopelículas}

El PET (polietilentereftalato), es un poliéster perteneciente a la familia de los termoplásticos. Inicialmente se utilizaban únicamente en la fabricación de fibras textiles, sin embargo por su versatilidad y por sus propiedades mecánicas y químicas comenzó a ser utilizado en un sin número de productos con distintas aplicaciones.

Actualmente, el PET es utilizado de forma excesiva y la mayor parte termina en los rellenos sanitarios y océanos, representando un problema ambiental debido a que por sus propiedades, su degradación es muy lenta. Además, la regulación mundial de su producción no ha sido adecuada porque continúa en aumento y no ha generado cambios en los hábitos de consumo de los habitantes.

El PET tiene la ventaja de ser un material de bajo precio y alta disponibilidad. Por su estructura es capaz de retener biomasa, y cuando es utilizado para estos fines, se beneficia al ambiente ya que en lugar de ser desechado en los residuos sólidos urbanos, es reciclado para el tratamiento de agua residual. Otra ventaja más es que el PET puede ser moldeado fácilmente y se pueden formar empaques de formas geométricas donde el área de contacto sea mucho mayor que en otros materiales como piedras, cascajos, etcétera. Se han desarrollado sistemas de tratamiento biológicos en los que el PET ha presentado resultados satisfactorios como material de soporte, alcanzando una eficiencia de $90-97 \%$.

\section{Ventajas del tratamiento anaerobio.}

En comparación con otros sistemas de tratamiento de aguas residuales, el tratamiento anaerobio presenta grandes ventajas que han sido estudiadas por algunos autores; y deben considerarse para quien diseñe una planta de tratamiento de aguas residuales. Algunas de ellas son:

- $\quad$ Al ser un proceso que opera en ausencia de oxígeno, no es necesaria la aireación del reactor.

- Alta capacidad de remoción de carga orgánica en afluentes de concentraciones iguales o mayores a $1,500 \mathrm{mg} / \mathrm{L}$ de DQO.

- Baja demanda de energía. 
- Producción de metano como fuente de energía que puede utilizarse en calderas o generadores eléctricos para elevar la temperatura del sistema.

- Menor volumen del reactor.

- $\quad$ En países donde la temperatura promedio es estable y alta no hay necesidad de calentar el reactor.

Bajo costo de inversión.

En comparación con los procesos aerobios, el tramiento anaerobio produce menos biomasa. Lo cual es favorable porque la inversión en el manejo y disposición de lodos será menor. Esto también implica menor requisito de nutrientes como nitrógeno y fósforo.

- La retención de biomasa es alta, por lo tanto no es necesario reciclar el lodo.

El lodo producido puede ser almacenado con facilidad en periodos de cargas orgánicas reducidas o paro del proceso.

\section{Desventajas del tratamiento anaerobio.}

Algunas de las desventajas del tratamiento anaerobio son las siguientes:

- Largos periodos de estabilización del proceso.

- Puede ser necesaria la adición de compuestos alcalinos para mantener un $\mathrm{pH}$ neutro. En aguas muy concentradas puede ser necesario una concentración de 2,0003,000 mg/L de $\mathrm{CaCO}_{3}$.

- Es necesario un tratamiento posterior al tratamiento anaerobio para mejorar la calidad del agua.

- No es posible la degradación biológica de nutrientes.

- $\quad$ Necesidad de temperaturas más altas para un mejor rendimiento.

Debido a la producción de ácido sulfhídrico y mercaptanos, estos procesos producen malos olores.
- Los tiempos de residencia son mayores que en los tratamientos aerobios.

- Se requiere un lodo granular para que el proceso sea más eficiente. De lo contrario, un lodo sin haber sido inoculado previamente tardará aproximadamente seis meses en arrancar.

La relación entre las bacterias filamentosas y las formadoras de flóculos es muy importante para una correcta sedimentación, ya que la predominancia de las bacterias filamentosas produce un fenómeno conocido como "bulking filamentoso", el cual impide que se formen los flóculos y la capacidad de sedimentación disminuya. Entre otros problemas de sedimentación, se encuentra el crecimiento disperso (efluente turbio sin formación de flóculos) y formación de flóculos "pin-point" o microflóculos (efluente turbio con formación de flóculos pequeños y débiles).

\section{Metododología}

\section{Microplanta}

El reactor anaerobio se construyó a partir de una Microplanta marca Boss Technology, con capacidad total de 2800 L. La Microplanta cuenta con dos compartimentos; de los cuales solo se utilizó uno para el tratamiento y tiene una capacidad aproximada de 1000 L. Como se observa en la figura 2 .

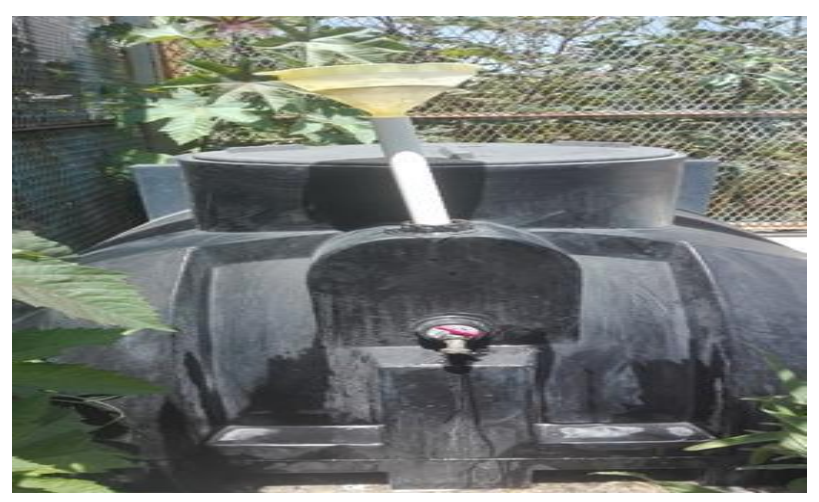

Figura 2 Microplanta marca Boss

Se armaron columnas de PET de tres distintas capacidades $600 \mathrm{~mL}, 1.2 \mathrm{~L}$ y $2 \mathrm{~L}$, las cuales fueron sobrepuestas y soportadas con tubo de PVC, como se observa en la Figura 3 


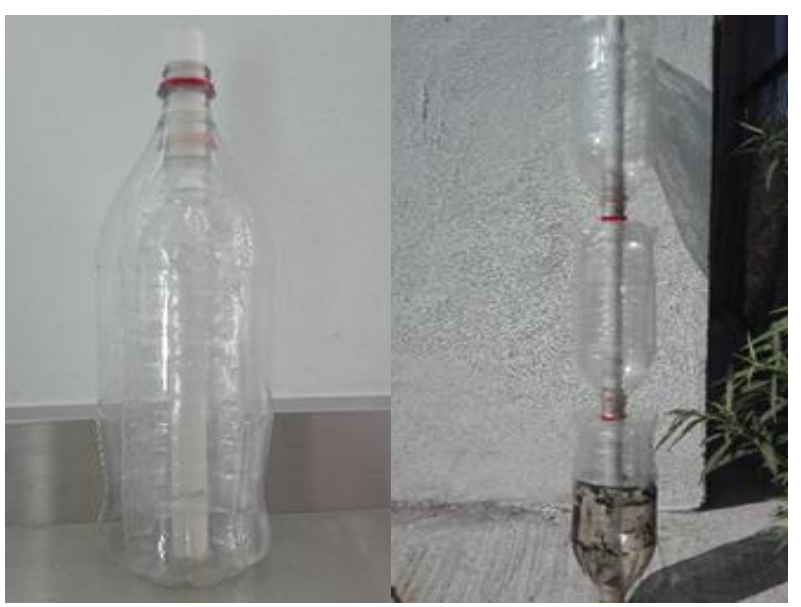

Figura 3 Armado de la estructura con pvc y botellas PET

Se adaptaron 57 columnas; dando un total de 131 botellas de cada capacidad, de las antes mencionadas. En la Figura 4 se puede visualizar la parte superior del reactor, después de haber sido instaladas todas las columnas de PET, que servirán de material de soporte para la formación de biopelículas. Se adaptó también una llave, con el fin de caracterizar el agua en un punto cercano a la entrada del influente, y después compararla con el efluente.

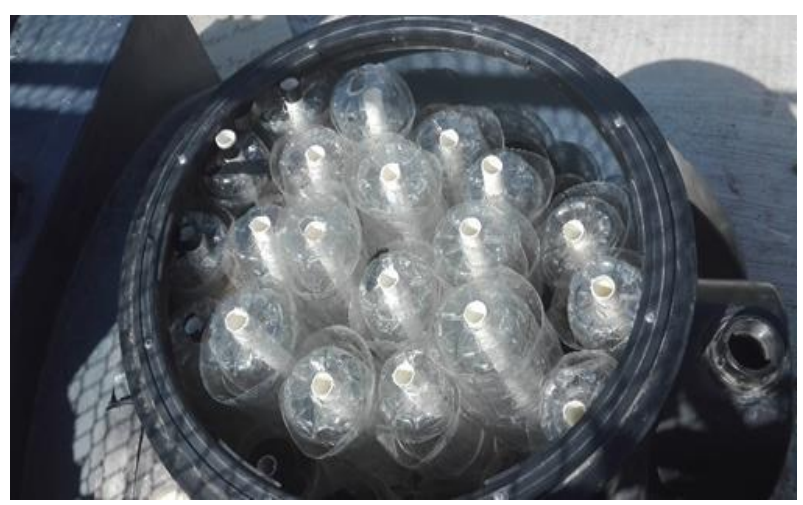

Figura 4 Vista superior del reactor con la estructura con pvc y botellas PET

\section{Inoculación de la Microplanta}

La inoculación del sistema se llevó a cabo utilizando lodo residual aerobio como inoculo, proveniente de la planta de tratamiento de agua residual del Campus Aeropuerto. El inoculo adicionado representó el $10 \%$ de su volumen total y la forma de alimentación fue utilizando un tubo de PVC como se muestra en la Figura 2, para que el flujo de entrada fuera de abajo hacia arriba con la intención de asegurar que el material de soporte estuviera en contacto con el lodo y posteriormente con el agua residual.

\section{Segunda Inoculación.}

Se llevó a cabo una nueva inoculación con lodos aerobios; posteriormente la estabilización tuvo un lapso de 20 días, en los cuales diariamente se midió el IVL para asegurar que el lodo presentara las características deseadas. Además se realizó la caracterización fisicoquímica habitual.

\section{Estabilización de la Microplanta}

Con el objetivo de adaptar los lodos aerobios a un ambiente anaerobio, el inoculo se sometió a un periodo de estrés de 30 días. El periodo de estrés se llevó a cabo con la adición de $10 \mathrm{~L}$ de agua residual diaria, lo cual permitió que los lodos tuvieran una cantidad mínima de carga orgánica para ser metabolizada mientras las bacterias comenzaban a acondicionarse al nuevo ambiente anaerobio.

Posterior a los 30 días del periodo de estrés (crecimiento de bacterias anaerobias), se aumentó el volumen adicionado a $20 \mathrm{~L}$ por un mes más. Durante esta etapa se monitorearon parámetros fisicoquímicos.

\section{Determinación del Tiempo de Retención Hidráulico}

El periodo de estabilización fue necesario para determinar el Tiempo de Retención Hidráulico (TRH), ya que con la experimentación se fue modificando el volumen de carga.

El TRH se calculó con la fórmula 1 siguiente:

$T R H=\frac{V r}{Q}$

TRH = Tiempo de Retención Hidráulico (s).

$\mathrm{Vr}=$ Volumen Total $\left(\mathrm{m}^{3}\right)$.

$\mathrm{Q}=$ Caudal (L/día).

Una vez inoculado la Microplanta se llevó a cabo la etapa de estabilización que duro 15 días a diferentes cargas, las cuales fueron a TRH de 33, 22 y 15 días. 


\section{Análisis fisicoquímico del agua en las tres etapas del tratamiento}

A lo largo de los tres tiempos de retención se analizaron tres muestras diferentes: MI (Influente - Agua Residual Cruda), MLL (Llave de muestreo), ME (Efluente). Se determinaron diferentes parámetros como $\mathrm{pH}$, Conductividad, Sólidos Disueltos Totales, Sólidos Totales, Temperatura, Turbidez y Demanda Quimica de Oxigeno (DQO). Dichos parámetros permitieron determinar la efectividad del tratamiento y llevar a cabo el análisis del agua

\section{Técnicas analíticas}

Los análisis realizados de $\mathrm{pH}$, Conductividad, Demanda Química de Oxigeno (DQO), Sólidos Disueltos Totales (SDT), Sólidos Totales (ST) Temperatura y Turbidez se basaron en las técnicas descritas en el APHA, AWWA, WPCF. Métodos normalizados para el análisis de aguas $\mathrm{y}$ aguas residuales.

\section{Mejoramiento de la calidad del agua residual tratada por filtración}

Se tomaron muestreos de los tres TRH diferentes para probar la efectividad de un filtro armado con una botella de PET, compuesto de carbón activado fino, arcilla y arena sílica y carbón activado granular (en orden ascendente) Como se muestra en la figura 5 .

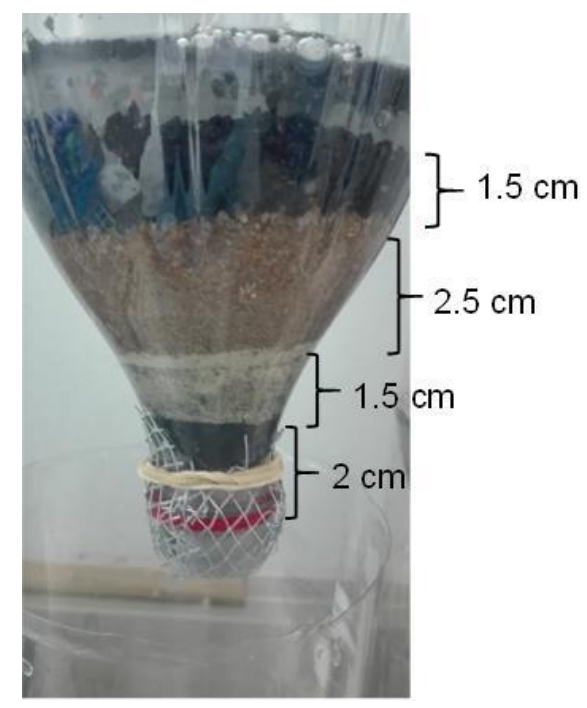

Figura 5 Filtro para mejorar la calidad del agua. Material filtrante de forma ascendente: carbón activado en polvo, arcilla, arena sílica, carbón activado poroso

Se realizaron los mismos análisis ya mencionados con el agua filtrada para comprobar si el filtro representaba algún cambio significativo en la calidad del agua tratada.

\section{Resultados}

\section{Inoculación y estabilización del sistema.}

El periodo de estabilización (incluida la segunda inoculación) duró 80 días. En general, los periodos de estabilización tienen una duración aproximada de 30-60 días pero este tiempo varía de acuerdo a las características ambientales en el reactor y de su estructura. El tiempo de estabilización se extendió más para alcanzar la estructura de lodo deseada y coinciden con los periodos de estabilización obtenidos por Elmitwalli y Otterpohl (76, 84 y 79 días). Esta etapa es determinante para que el proceso sea efectivo y una alternativa para reducir el tiempo de estabilización anaerobia es el de inclur un pre tratamiento térmico, ultrasónico, con microondas, Fenton, oxidación húmeda, fotocatálisis, entre otros .

En la primera etapa de estabilización (60 días) se realizaron 20 pruebas y 14 en el segundo periodo (20 días). En la tabla 3 se muestran los promedios obtenidos de los parámetros analizados.

\begin{tabular}{|l|l|l|l|l|l|l|}
\hline & \multicolumn{3}{|c}{$\begin{array}{c}\text { Periodo de } \\
\text { Estabilización }\end{array}$} & \multicolumn{3}{c|}{$\begin{array}{l}\text { Segundo Periodo de } \\
\text { Estabilización }\end{array}$} \\
\hline & Media. & $\begin{array}{l}\text { Desv. } \\
\text { Estándar }\end{array}$ & Rango & Media & $\begin{array}{l}\text { Desv. } \\
\text { Estándar }\end{array}$ & Rango \\
\hline pH & 7.7 & 0.135 & $7.4-$ & 7.4 & 0.323 & $\begin{array}{l}6.7- \\
7.9\end{array}$ \\
\hline $\begin{array}{l}\text { Temperatura } \\
\left({ }^{\circ} \mathbf{C}\right)\end{array}$ & 23.0 & 3.028 & $18.0-$ & 24.7 & 1.600 & $\begin{array}{l}21.0- \\
27.0\end{array}$ \\
\hline $\begin{array}{l}\text { Sólidos } \\
\text { Totales (g/L) }\end{array}$ & 6.7 & 82.30 & $\begin{array}{l}2.6- \\
9.6\end{array}$ & 10.2 & 1.145 & $\begin{array}{l}8.5- \\
12.2\end{array}$ \\
\hline
\end{tabular}

Tabla 1 Análisis de los lodos durante los periodos de estabilización

\section{pH, temperatura y conductividad.}

El rango de $\mathrm{pH}$ desde el inicio del proceso de estabilización (Tabla 1) hasta que se terminó de analizar el último tiempo de retención (Tabla 2) fue de 6.7-8.1, y a pesar de que el rango óptimo para el crecimiento de las bacterias metanogénicas va de 6.6-7.2; Von Sperling y Lemos han reportado que con un $\mathrm{pH}$ de 6.0-8.0 se puede alcanzar estabilidad en la producción de metano aunque deben evitarse valores por debajo de 6.0 y por encima de 8.3 , ya que pueden inhibir el crecimiento de bacterias metanogénicas. 


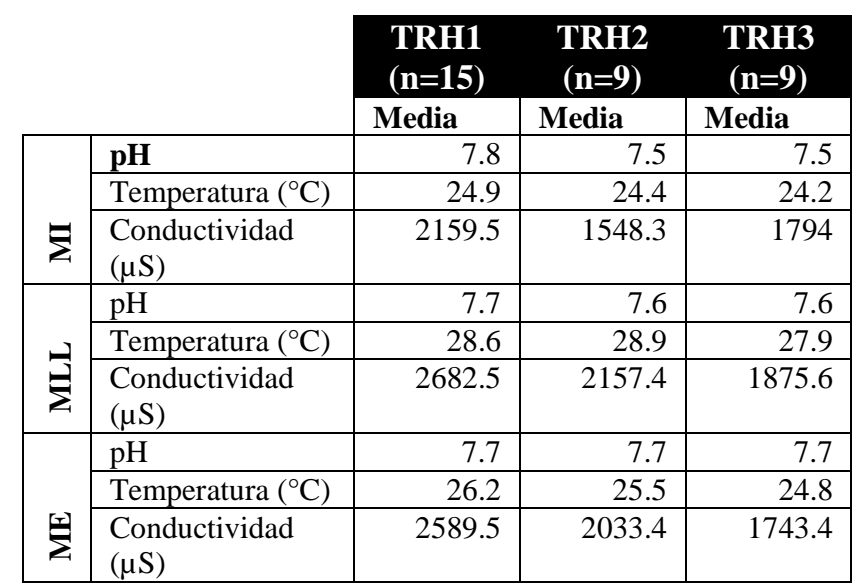

Tabla 1 Parámetros fisicoquímicos de los tres parámetros en los tres tiempos de retención hidráulica

\section{Turbidez}

En lo que respecta al parámetro de Turbidez, medidades en unidades Nephelometric Turbidity Unit (NTU) en la Gráfica 1, se puede notar una tendencia de las muestras de la llave y el efluente con respecto a las muestras del influente, durante los tres tiempos de retención.

a)

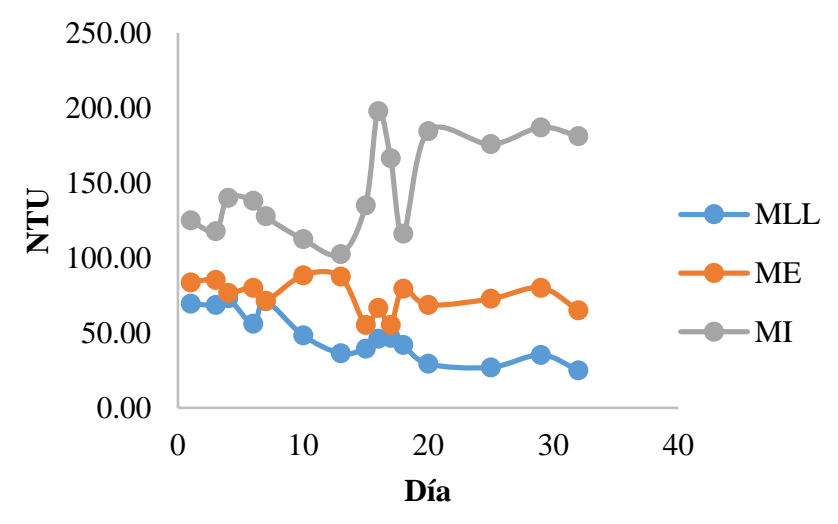

b)

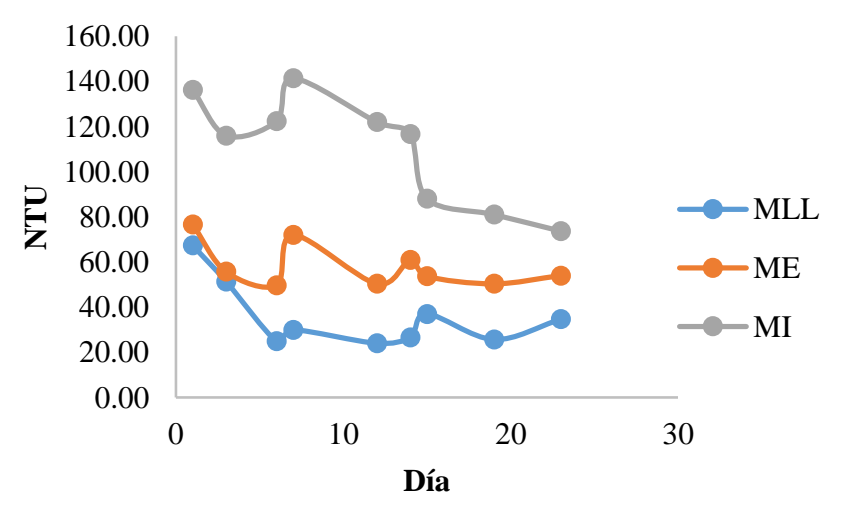

c)

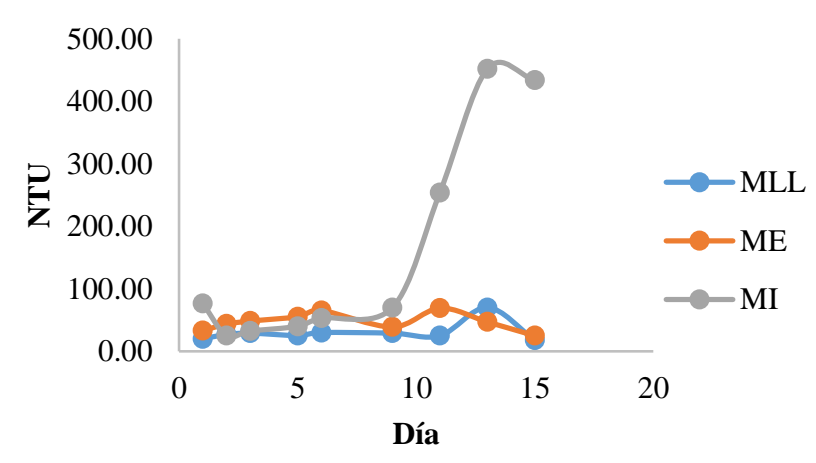

Gráfica 1 Valores de turbidez en las tres muestras. a) Primer tiempo de retención, b) Segundo Tiempo de Retención, c) Tercer Tiempo de Retención

\section{Demanda Química de Oxígeno (DQO)}

En el ensayo de la DQO determina la cantidad de oxígeno necesario para oxidar químicamente las sustancias orgánicas en el agua. Por muchos años no se reguló este parámetro, pero ha adquirido gran importancia en todo el mundo, ya que representa la cantidad de compuestos químicos en agua que no han podido ser degradados de forma biológica.

La Gráfica 2, indica la cantidad de DQO en las tres muestras de agua durante los tres tiempos de retención, así como los límites máximos permisibles para descarga en suelo para riego de áreas verdes e infiltración y otros riegos, establecidos en el proyecto de norma PROY-NOM-001-Semarnat-2017.

a)

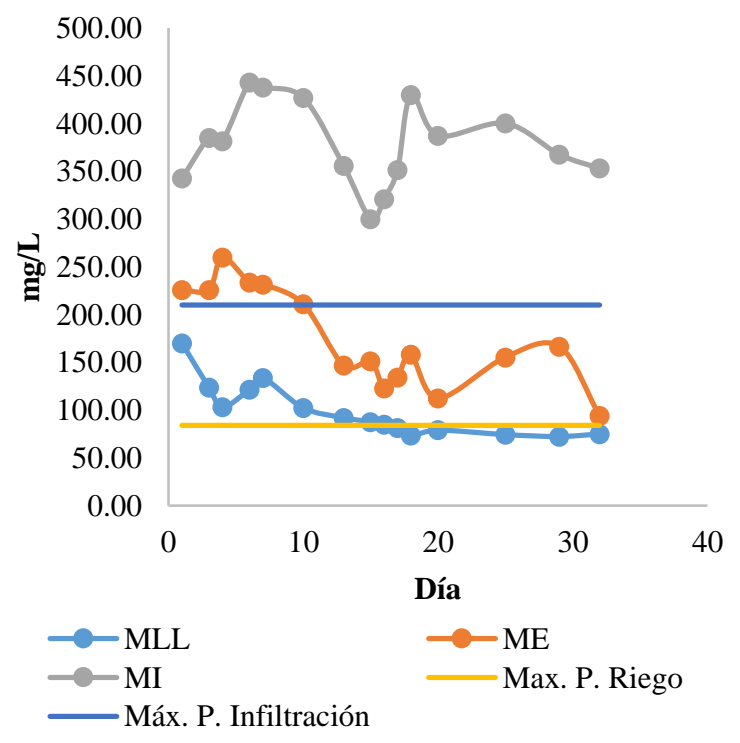


b)

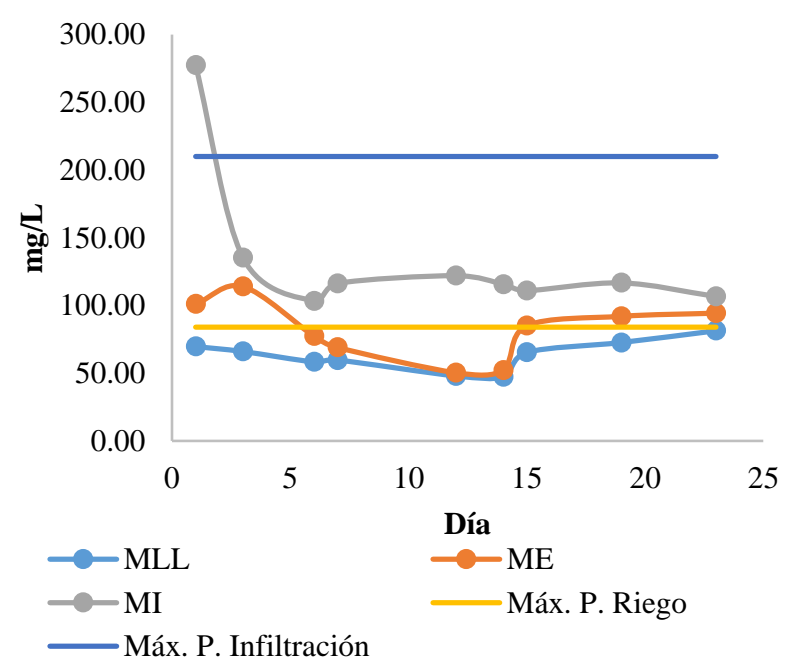

c)

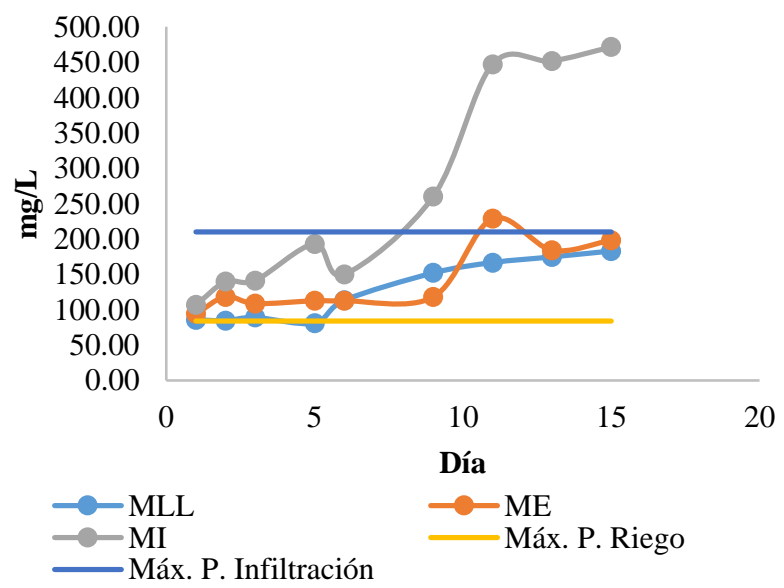

Gráfica 2 Demanda Química de Oxígeno de las tres muestras. a) Primer periodo de retención, b) Segundo Tiempo de Retención, c) Tercer Tiempo de Retención. Máx. Perm. De acuerdo al PROY-NOM-001-Semarnat2017. Descarga en suelo de riego de áreas verdes e infiltración

\section{Sólidos Suspendidos Totales (SST).}

De una forma similar a la DQO, los SST presentan un comportamiento variable, como se presenta en las tres gráficas de la Gráfica 3. En el segundo tiempo de retención (Gráfica 3b) la concentración de SST es más estable y la estabilidad continúa en el tercer tiempo de retención (Gráfica 3c) hasta el día de 9 en la que la DQO del influente aumenta y con ello las muestras tratadas, de la misma forma que ocurre en los demás parámetros analizados. a)

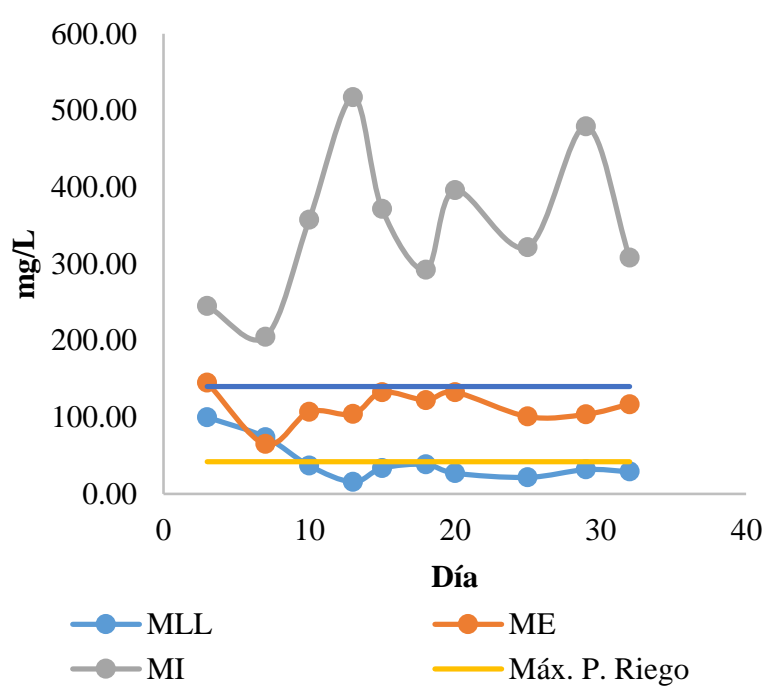

b)

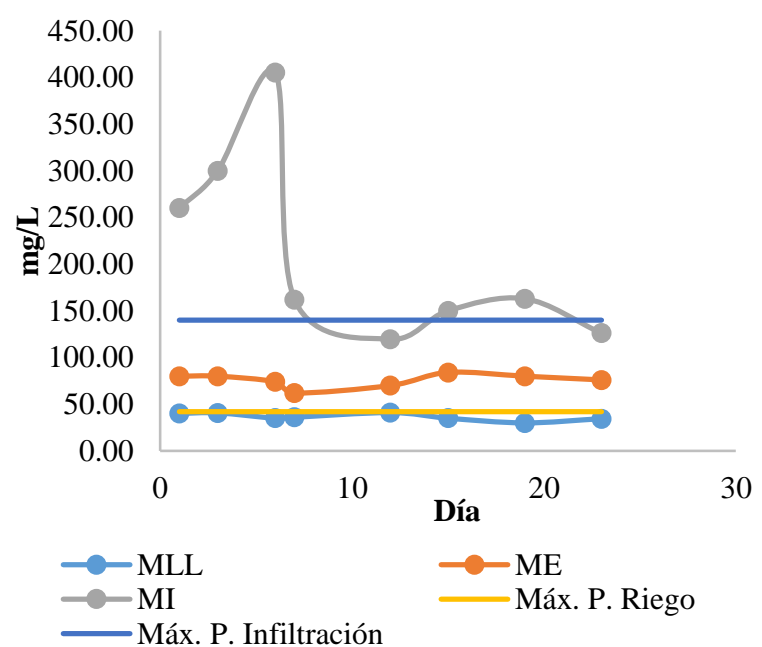

c)

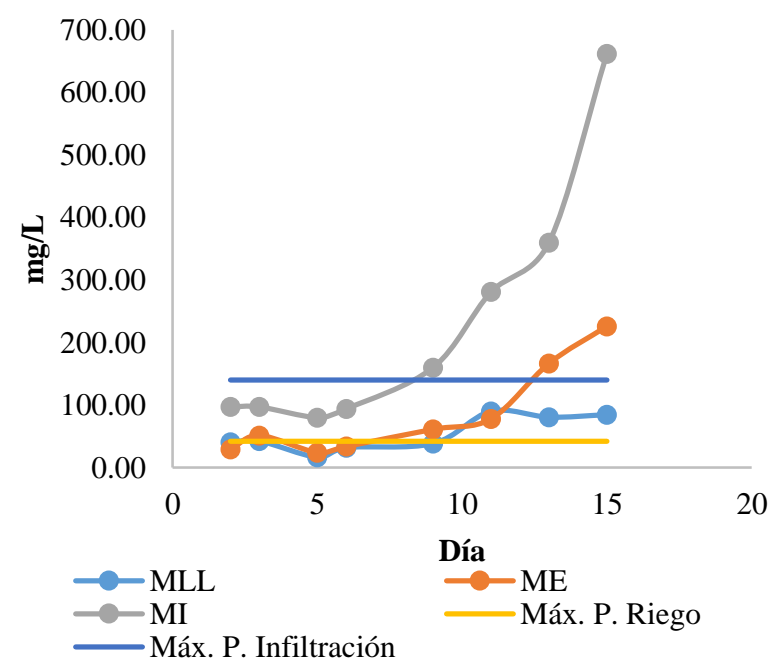

Gráfica 3 Sólidos Suspendidos Totales en las tres muestras. a) Primer tiempo de retención, b) Segundo tiempo de retención, c) Tercer tiempo de retención. Máx. Perm. De acuerdo al PROY-NOM-001-Semarnat-2017. Descarga en suelo de riego de áreas verdes e infiltración 


\section{Mejoramiento de la calidad del agua tratada por medio de filtración}

En comparación con el sistema de tratamiento anaerobio descrito; el sistema de filtración propuesto mejoró considerablemente la calidad del agua con un porcentaje mayor de remoción de DQO y SST, como se expone en la Figura 9. En cada tiempo de retención se comparan los porcentajes de remoción de las muestras filtradas $\mathrm{y} \sin$ filtrar.

a)

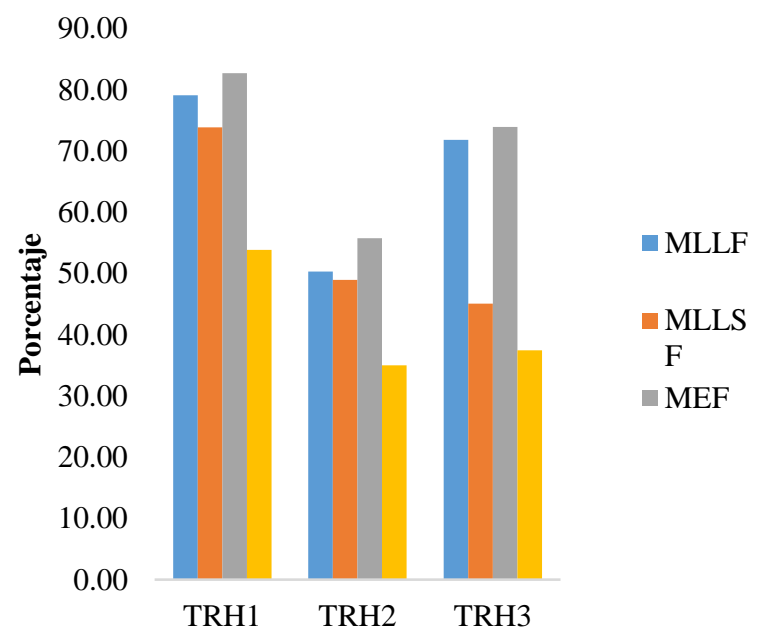

b)

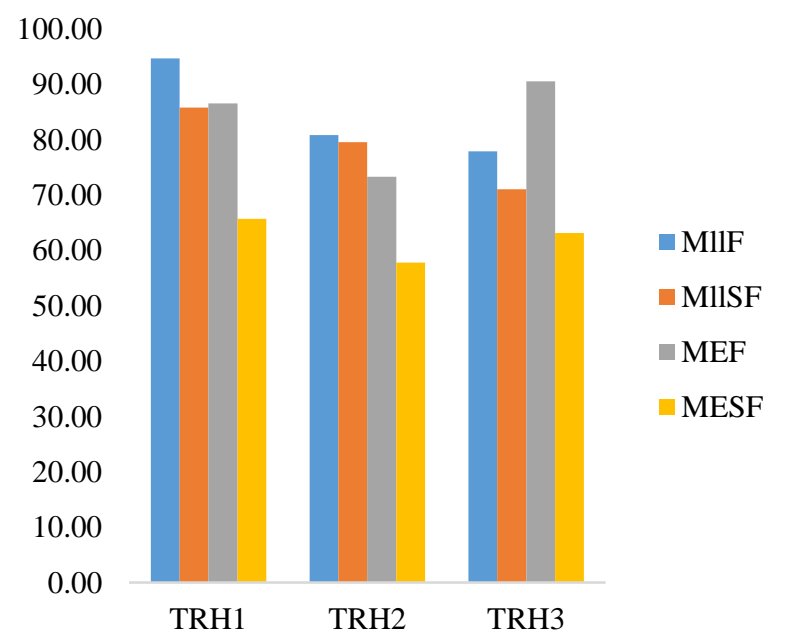

Figura 9 Porcentaje de remoción en las muestras filtradas y sin filtrar. a) DQO, b) SST

\section{Agradecimiento}

El primer agradece a los proyectos FOFI-UAQ 2018 por habernos financiado el proyecto FIN201810.

\section{Conclusiones}

\section{Inoculación y estabilización del sistema.}

En un inicio el lodo tenía una estructura granular, lo cual era deseable ya que esta estructura permanece intacta incluso cuando hay estrés hidráulico. Sin embargo, el lodo comenzó a adquirir una estructura floculenta, y la desventaja de esta estructura de acuerdo a Hulshoff es que los flóculos tienden a descomponerse con mayor facilidad, incluso cuando el mezclado es suave.

El proceso de granulación es bastante complejo ya que contribuyen las fuerzas químicas, físicas y biológicas. Liu y colaboradores, describieron este proceso en un modelo general que involucra 4 pasos para la formación de los gránulos; en este modelo se resalta lo determinantes que son el movimiento físico para que las bacterias se adhieran entre ellas, las fuerzas de atracción iniciales (físicas, químicas y bioquímicas), las fuerzas microbianas que permiten madurar a los agregados celulares y la estructura tridimensional de los agregados microbianos en el estado estacionario. Aunque se han reportado periodos de estabilización de aproximadamente 80 días, para reducir este tiempo será necesario que se monitoreen con mayor profundidad los parámetros antes mencionados.

En general, los valores de $\mathrm{pH}$ reportados no ponen en peligro el proceso anaerobio, no obstante se observó que los valores más bajos se reportaron durante el segundo periodo de estabilización (después de la segunda inoculación). Se puede inferir que esta ligera disminución de $\mathrm{pH}$ se debe a las etapas de acidogénesis y acetogénesis en las que se generan ácidos orgánicos en los procesos anaerobios. Posterior a la estabilización, no se obtuvieron valores inferiores a 7.2.

\section{pH, temperatura y conductividad.}

La temperatura fue variable en relación al estado del tiempo, pero se pudo notar que en las muestras tomadas de la llave de muestreo se registraron valores más altos, al igual que en la muestra del efluente; lo cual es favorable puesto que se puede asegurar que dentro del reactor se conservaba la temperatura adecuada para el desarrollo de las bacterias metanogénicas. 
La conductividad eléctrica presentó valores mayores en las tres muestras del primer tiempo de retención, en promedio en el segundo tiempo de retención se obtuvo un porcentaje de reducción de $23.12 \%$ y $26.56 \%$ en el tercero. Los valores de conductividad, tienen relación con la cantidad de sólidos disueltos en el agua ya que la conductividad representa la capacidad de una solución para conducir corriente eléctrica y ésta depende de los iones presentes. Por ello es que a medida que la conductividad disminuye, también disminuye la cantidad de sólidos disueltos totales. Los porcentajes de reducción de sólidos disueltos totales son $21.11 \%$ en el segundo tiempo de retención y $27.26 \%$ en el tercero; valores que se aproximan a los obtenidos en la conductividad.

\section{Turbidez}

Se puede apreciar que en el segundo tiempo de retención los valores descienden y las muestras tratadas no tienen un cambio muy significativo, por lo cual el porcentaje de reducción es menor que en el primer tiempo de retención. En el tercer tiempo de retención, la turbidez del agua de entrada sube drásticamente después del día 9 ya que en esta fecha se retomaron las actividades en el Campus Aeropuerto y se elevó la cantidad de sólidos suspendidos en el agua. A pesar de esta variación, la turbidez en las muestras tratadas no se elevó por encima de 80 NTU, lo que indica la capacidad del sistema para seguir tratando los sólidos suspendidos a pesar de las condiciones de entrada.

\section{Demanda Química de Oxígeno (DQO)}

La Figura 7, indica la cantidad de DQO en las tres muestras de agua durante los tres tiempos de retención, así como los límites máximos permisibles para descarga en suelo para riego de áreas verdes e infiltración y otros riegos, establecidos en el proyecto de norma PROYNOM-001-Semarnat-2017. Después del día 10 del primer periodo de retención, tanto las muestras de la llave y del efluente son aptas para descarga en suelo de infiltración, se puede observar también en la gráfica que después del día 20 hay un ligero aumento en la DQO de la muestra del efluente. La razón es porque durante la etapa de fermentación ácida, los componentes orgánicos complejos en su proceso de degradación se descomponen en ácidos orgánicos de cadena simple como el ácido acético, propiónico y butílico.
Esta producción de ácidos orgánicos se ve reflejada en la DQO, debido a que estos compuestos ejercen una demanda química de oxígeno. Es por ello muy probable que en los primeros periodos de tratamiento anaerobio la DQO se incremente (Ramahlo, 1990).

Posteriormente los valores de DQO se mantuvieron por debajo de los límites máximos para descarga en suelo de infiltración durante los dos siguientes tiempos de retención a excepción de un punto en el tercer tiempo de retención.

Para que el agua tratada pueda ser descargada en suelo para riego de áreas verdes, es necesario que se mejore el sistema y se alcance una estabilidad en los valores de DQO por debajo del límite permisible, ya que en este sistema sólo algunos puntos son aceptables, principalmente para las muestras de la llave.

\section{Remoción de DQO y SST}

Los parámetros examinados, se determinó el porcentaje de remoción de la DQO y SST (Figura 9), ya que estas variables son las que se encuentran reguladas en el PROY-NOM-001Semarnat-2017 y en la NOM-003SEMARNAT-1997, por ser de especial interés en la calidad de agua para descarga y reúso. De la DQO (Figura 9a) se obtuvieron porcentajes de remoción en la muestra de la llave de $73.85 \%$ (TRH1), 48.97\% (TRH2), 45.04\% (TRH3) y en la muestra del efluente de $53.85 \%$ (TRH1), $34.98 \%$ (TRH2), $37.46 \%$ (TRH3). Mientras que en las concentraciones de SST (Figura 9b) se alcanzaron porcentajes de remoción en la muestra de la llave de $85.80 \%$ (TRH1), 79.60\% (TRH2), $71.09 \%$ (TRH3) y en la muestra del efluente de $65.70 \%$ (TRH1), 57.77\% (TRH2), $63.15 \%$ (TRH3).

Se diseñó un sistema de tratamiento anaerobio de contacto para el tratamiento de aguas residuales domésticas del Campus Aeropuerto mediante el uso de botellas de PET como material de soporte para las biopelículas. El pH y la temperatura de las muestras de agua residual tratada se encontraron en un rango aceptable para un sistema de tratamiento anaerobio adecuado; pero los valores de conductividad se elevaron después del tratamiento biológico. 
Tanto la DQO como los SST tuvieron buenos porcentajes de remoción en los tres tiempos de retención de las muestras tratadas remoción. Mayores de 45\% (muestra de la llave) y 34\% (muestra del efluente) para DQO y mayores de $71 \%$ (muestra de la llave) y $57 \%$ (muestra del efluente) para SST. La turbidez presentó un comportamiento similar.

Se logró mejorar la calidad del agua tratada con el sistema de filtración diseñado para los siguientes parámetros: turbidez, conductividad, DQO y SST. No obstante, el pH se elevó en las muestras filtradas.

Las muestras analizadas por la Unidad de Servicios Químicos Analíticos y Unidad de Servicios Clínicos, comprobaron la efectividad del sistema de tratamiento en los valores de $\mathrm{DBO}_{5}$ y grasas y aceites; sin embargo se sugiere adecuar un sistema de tratamiento terciario en el que se incluya la filtración y cloración para alcanzar valores aptos para DQO y coliformes fecales.

\section{Referencias}

Abdel-raouf, N., Al-Homaidan, A. A., Ibraheem, I. B. M. Microalgae and wastewater treatment. Saudi Journal of Biological Sciences. 2012; 19, 257-275.

Acosta, Y. L., Obaya, M. C. La Digestión Anaerobia. Aspectos teóricos. Parte I. ICIDCA. Sobre los Derivados de la Caña de Azúcar. 2005; $39,35-48$.

Anjum, M., Al-Makishah, N.H., Barakat, M.A. Wastewater sludge stabilization using pretreatment methods. Process Safety and Environmental Protection. 2016; 102, 615-632.

ATSDR. Toxicological profile for benzene. Atlanta, Georgia: Agency for Toxic Substances and Disease Registry, 2007.

Aragón, C. A. Optimización del proceso de lodos activos para reducir la generación de fangos residuales (Tesis Doctoral). Cádiz: Universidad de Cádiz, 2009.

Betancourt, W. Q., Querales, L. J. Parásitos Protozoarios Entéricos en Ambientes Acuáticos: Métodos de Concentración y Detección. Interciencia. 2008; 33, 418-423.
Cámara, K. C., Laines, J. R. La Digestión Anaerobia y la Bioquímica. Kuxulkab. 2011; 17, 89-95.

CEA. La Memoria del Agua. Trabajos, retos y logros de la Comisión Estatal de Aguas de Querétaro 2001-2009. Querétaro: Comisión Estatal del Agua, 2009.

Chávez, M. E. Diseño y cálculo de un tren de tratamiento biológico para aguas residuales urbanas usando la tecnología de lecho granular expandido (Tesis de Maestría). México, D.F.: Instituto Politécnico Nacional, 2010.

CONAGUA. Estadísticas del agua en México. México, D.F. : Comisión Nacional del Agua, 2011.

CONAGUA. Programa Nacional Hídrico. 20142018. México, D.F. : Comisión Nacional del Agua, 2013.

CONAGUA. Atlas del agua en México 2016. México, D.F. : Comisión Nacional del Agua, 2016.

Dauvergne, P. Why is the global governance of plastic failing the oceans? Global Environmental Change. 2018; 51, 22-31.

Dick, R. I., Vesilind, P. A. The Sludge Volume Index: What is it? Water Pollution Control Federation. 1969; 41, 1285-1291.

Eckenfelder, W. W. Industrial Water Pollution Control. 3a Edición. Toronto: Mc-Graw Hill, 2000. 50-53.

Espinosa, M. C. Remoción de materia orgánica y benceno de aguas residuales mediante lodos activados acoplados con proceso foto Fenton (Tesis de Maestría). Querétaro, México.: Universidad Autónoma de Querétaro, 2017.

Elmitwalli, T. A., Otterpohl, R. Anaerobic Biodegradability and treatment of grey water in upflow anaerobic sludge blanket (UASB) reactor. Water Research. 2007; 41, 1379-1387.

Fall, C.; Loaiza, J.; Esparza, M.; Martínez, L. Evaluación de un clarificador secundario en una planta de tratamiento de aguas residuales. Ingenierías; 35, 13-19. 
FAO-Aquastat. Sistema de Información sobre el Uso del Agua en la Agricultura y el Medio Rural de la FAO. Food and Agriculture Organization of the United Nations, 2016.

Govoreanu, R. Activated sludge flocculation dynamics: on-line measurement methodology and modelling (Tesis Doctoral). Ghent, Bélgica: Universiteit Gent, 2004.

Hulshoff, L. The phenomenon of granulation of anaerobic sludge (Tesis Doctoral). Wageningen: Wageningen University and Research, 1989.

Huser, B. A., Wuhrmann, K., Zehnder, A. J. B. Methanothrix soehngenii gen. Nov. Sp. Nov., a new acetotrophic non-hydrogen-oxidyzing methane bacterium. Springer-Verlag. 1982; 1-9.

Jiménez, B.E. La contaminación Ambiental en México. México: Limusa, 2005; 259.

Joel, C., Kiprop, E. K., Mwamburi, L. A. Effect of seasonal variation on performance of conventional wastewater treatment system. Journal of Applied \& Environmental Microbiology. 2017; 5, 1-7.

Kiely, G. Ingeniería Ambiental. Fundamentos, entornos, tecnologías y sistemas de gestión. Madrid: Mc Graw Hill, 1999; 105,-106, 630639, 749-750.

Kostyla, C., Bain, R., Cronk, R., Bartram, J. Seasonal variation of fecal contamination in drinking water sources in developing countries: A systematic review. Science of the Total Environment, 2015; 514, 333-343.

Lapo, B., Romero, H. PET y PP usado como medios de crecimiento de Biopelícula Fija aplicada al Tratatamiento Aerobio. COBEQ, 2016; 20, 1-9.

Liu, Y., Xu, H.L., Yang, S.F., Tay, J.H. Mechanisms and models for anaerobic granulation in upflow anaerobic sludge blanket reactor. Water Research. 2003; 37, 661-673.

Mendoza, M. Y., Rodríguez, J. A. Reactor Aerobio con Medio de Soporte Fijo utilizando botellas de PET. Espacio I+D, Inovación más Desarrollo. 2016; 12: 105-116.
Mendoza, M.Y. Acoplamiento de un sistema biológico aerobio y un proceso avanzado de oxidación para el tratamiento de un efluente acuoso (Tesis de Maestría). Querétaro, México: Universidad Autónoma de Querétaro, 2016.

Metcalf, L., Eddy, H., comp. Wastewater Engineering Treatment and Reuse. 4a. edición. Nueva York: Mc-Graw Hill, 2003; 10-14, 602604, 635, 684-685.

Mohlman, F.M. The Sludge Index. Sewage Works J. 1934; 6, 119-122.

Noyola, A., Morgan-Sagastume, J.M., Güereca, L.P. Selección de tecnologías para el tratamiento de aguas residuales municipales. Guía de apoyo para ciudades pequeñas y medianas. México: Universidad Autónoma de México. Instituto de Ingeniería, 2013; 12-13.

Peñuela, G., Morató, J. Manual de Tecnologías Sostenibles en Tratamiento de Aguas. Cataluña: TECSPAR, 2009; 89-101.

Rajeshwari, K. V, Balakrishnan, M., Kansal, A., Lata, K., Kishore, V. V. N. State-of-the-art of anaerobic digestion technology for industrial wastewater treatment. Renewable \& Sustainable Energy Reviews. 2000; 4, 135-156.

Ramalho, R.S. Tratamiento de aguas residuales. Barcelona: Reverté, 1990; 110, 503-504, 509, 518-519, 531-532.

Spencer, P. The Biological Basis of Water Treatment. Glasgow: Strathkelvin Instruments Ltd, 2005; 3-6.

Velázquez, M. C. Organismos filamentosos y su relación con la degradación de materia orgánica y nutrientes bajo condiciones específicas de operación. México, D.F. : Universidad Nacional Autónoma de México, 2006.

Von Sperling, M, Lemos, C. A. Biological Wastewater Treatment in Warm Climate Regions. Volume one. London: IWA Publishing, 2005; 312-314, 446-449, 660.

$\mathrm{Wu}, \mathrm{W}$. Cultivation of anaerobic granular sludge in UASB reactors with aerobic activated sludge as seed. Water Research, 1987; 789-799. 
WWAP. Informe Mundial de las Naciones Unidas sobre el Desarrollo de los Recursos Hídricos 2017. Aguas residuales: El recurso no explotado. París: UNESCO, 2017.

WWDR. Informe de las Naciones Unidas sobre los recursos hídricos en el mundo 2015. Agua para un Mundo Sostenible: Datos y Cifras. Perusa: UNESCO, 2015. 